\title{
Transmissão Geracional da Profissão na Família: Repetição e Diferenciação
}

\author{
Maria Elisa Almeida \\ Andrea Seixas Magalhães \\ Terezinha Féres-Carneiro \\ Pontifícia Universidade Católica do Rio de Janeiro \\ Rio de Janeiro, RJ, Brasil
}

\begin{abstract}
RESUMO
Neste estudo, discute-se o processo de transmissão geracional da profissão na família. Foi realizada uma pesquisa qualitativa, na qual foram entrevistados quinze sujeitos, de três gerações que seguiram a mesma profissão, de cinco famílias - advogados, médicos, músicos, professores de teatro, psicanalistas. Da análise do conteúdo das entrevistas emergiram as seguintes categorias: naturalidade do processo de escolha profissional; a necessidade de diferenciação; o peso do nome e do sobrenome; a figura mítica familiar; liberdade de escolha na contemporaneidade; valores transmitidos no cotidiano; lealdade ao amor pela profissão. Neste trabalho, são apresentadas as três primeiras categorias. Concluise que a repetição da escolha profissional na família é percebida como um processo naturalizado, como um elemento de continuidade geracional. Destaca-se, ainda, a responsabilidade percebida quanto à transmissão do sobrenome vinculado à profissão, e também a necessidade de diferenciação dos membros da família e da apropriação do legado familiar com preservação da individualidade.
\end{abstract}

Palavras-chave: Transmissão geracional; Família; Profissão.

\begin{abstract}
Generational Transmission of Profession in the Family: Repetition and Differentiation

In this study we discuss the process of generational transmission of profession in the family. Fifteen individuals were interviewed, from three generations, who had followed the same profession. Participants were from five families lawyers, doctors, musicians, acting teachers, psychoanalysts. From the content analysis of the interviews the following categories emerged: naturalization of the process of career choice; need for differentiation; the weight attributed to the family name; mythical family figure; freedom of choice in contemporaneity; values transmitted in daily life; loyalty to the love for the profession. In this work the three former categories are presented. We conclude that repetition in the choice of profession in the family is perceived as a naturalized process, highlighting the responsibility in the transmission of the family name associated to the profession, the need for differentiation and for appropriation of the family legacy, while preserving individuality.
\end{abstract}

Keywords: Generational transmission; Profession; Family.

\section{RESUMEN}

\section{Transmisión Generacional de la Profesión en la Familia: Repetición y Diferenciación}

En este estudio se discute el proceso de transmisión generacional de la profesión en la familia. Fueron entrevistados quince sujetos, de tres generaciones, que siguieron la misma profesión, pertenecientes a cinco familias - abogados, médicos, músicos, profesores de teatro, psicoanalistas. Del análisis del contenido de las entrevistas emergieron las categorías: naturalidad del proceso de elección profesional; necesidad de diferenciación; peso del nombre y del apellido; figura mítica familiar; libertad de elección en la contemporaneidad; valores transmitidos en el cuotidiano; y lealtad al amor por la profesión. En este trabajo son presentadas las primeras tres categorías. Se concluye que la repetición de la elección profesional en la familia es percibida como un proceso naturalizado, destacándose, todavía, la responsabilidad cuanto a la transmisión del apellido vinculado a la profesión, la necesidad de diferenciación y de apropiación del legado familiar con preservación de la individualidad.

Palabras clave: Transmisión generacional; Profesión; Familia. 
A família constitui-se como um meio privilegiado de transmissão. Seja da transmissão da própria vida, seja de um nome, do sobrenome, do patrimônio, da educação, da cultura ou de uma profissão. O processo de transmissão na família é fundamental para a construção de si, isto é, para a formação da identidade do indivíduo. As gerações da família transmitem conteúdos que visam assegurar a sobrevivência do grupo familiar através do tempo.

O processo de transmissão pode começar bem antes de a criança ser concebida, quando os pensamentos, sentimentos e fantasias da mãe - e da família começam a preparar o lugar que esse filho ocupará em sua vida (Bowen, 1965). Ou seja, o indivíduo, mesmo antes de nascer, já recebe uma projeção familiar e já vem ao mundo inserido em uma história preexistente da qual ele é herdeiro e também prisioneiro (Falcke e Wagner, 2005).

A transmissão geracional torna-se evidente através da repetição dos padrões familiares e é nessa transmissão que reside a sobrevivência e a perpetuação da família. Segundo Gaulejac (2009), a repetição, seja ela consciente ou inconsciente, de comportamentos, sintomas ou escolhas na família é uma manifestação do vínculo com as gerações anteriores e é de grande necessidade e importância para a construção do indivíduo enquanto sujeito. Ele precisa desse referencial porque é elemento constitutivo de sua identidade.

Conforme Minuchin (1993), é a família que nos dá o sentido de pertencimento e de diferenciação. Assim, a identidade do indivíduo se constitui nesse bojo de relacionamentos e conteúdos que são transmitidos e que vão definir o seu lugar na família. De acordo com Andolfi, Angelo, Menghi e Nicolo-Corigliano (1984), a necessidade de diferenciação do indivíduo, também entendida como a sua necessidade de autoexpressão, com o passar do tempo, irá fundir-se com a necessidade de coesão e manutenção da unidade no grupo.

Desse modo, o indivíduo vive, num primeiro momento, um estado de indiferenciação e, na progressão gradual do desenvolvimento psíquico, ele busca a individuação e a separação, visando encontrar o seu espaço pessoal e a sua identidade. O grau de diferenciação que o indivíduo atinge depende da interação mãe-filho e também dos outros processos interativos ocorridos no interior do sistema familiar. Assim, a diferenciação será mais difícil quando houver conflitos entre os próprios desejos do indivíduo e as expectativas sobre ele colocadas (Andolfi et al., 1984).

A diferenciação do self é fundamental para o desenvolvimento saudável do indivíduo, uma vez que se refere à afirmação da singularidade, ao direito de expressar a sua individuação e ao seu direito de pensar e expressar-se, independentemente dos valores transmitidos por sua família. Por outro lado, pertencer também é de extrema importância, pois significa participar, ser membro da família e partilhar as suas crenças, mitos, valores e legados (Martins, Rabinovich e Silva, 2008).

As gerações mais velhas, ao transmitirem os valores e os mitos familiares, delegam aos membros do sistema familiar um papel e um destino, atribuídos pelas leis familiares. Segundo Boszormenyi-Nagy e Spark (1984), cada família tem suas leis que vão sendo herdadas ao longo do ciclo de vida familiar. Os autores chamam esses conteúdos de "lealdades invisíveis", pois são conteúdos que perpassam as gerações, muitas vezes sem serem nomeados explicitamente.

A noção de lealdade é fundamental para compreender a estrutura relacional das famílias, bem como o cumprimento dos legados e as repetições que ocorrem de geração a geração, tanto concernentes a comportamentos, como a atitudes ou, até mesmo, a escolhas. Os compromissos de lealdade tecem uma rede resistente que mantém unidas as partes do sistema familiar (Costa, 2010). As lealdades nesse contexto são importantes porque marcam o pertencimento do indivíduo ao grupo e garantem a sobrevivência do grupo familiar através das gerações.

O processo de delegação está diretamente ligado ao conceito de lealdade familiar e pressupõe que o membro deve assumir o compromisso de corresponder às regras e às expectativas do grupo familiar e cumprir a missão que lhe foi atribuída (Bucher-Maluschke, 2008). O legado é, assim, estabelecido como um mandato veiculado através das gerações, que tem por função transmitir às gerações seguintes os principais aspectos da família, aos quais se espera que seja dada continuidade (Falcke e Wagner, 2005).

A escolha do nome do filho, muitas vezes, obedece às lealdades invisíveis. Isto pode ser notado quando há repetição de nomes na família, ou, por exemplo, em casos de predominância de nomes com sentidos religiosos (Krom, 2000). De acordo com Schutzemberger (2011), o nome próprio é escolhido, muitas vezes, a partir da dinâmica familiar. Segundo a autora, os pais e familiares participam da construção psíquica precoce da criança ao escolher dar-lhe o nome de algum ascendente como uma homenagem, o nome de um membro da família que já faleceu, um nome que seja a junção do nome do pai com o da mãe ou o nome de um santo, por exemplo. Desta forma, a criança já nasce com uma espécie de missão ou de reparação a ser realizada ao longo da vida.

O sobrenome, por sua vez, indica de quem e de onde se vem, especificando a origem e filiação do indivíduo. 
O nome de família assinala a inscrição do membro familiar em uma linhagem. Além das significações que o nome próprio imprime, o sobrenome que a família carrega também pode mostrar-se muito expressivo, quer por significar o nome de um determinado local ou de uma profissão, quer por ser um sobrenome conhecido em alguma área. Nesse caso, a pessoa já carrega consigo o peso do sobrenome, e a carga de fazer jus ao que foi construído pelos ascendentes (Ducommun-Nagy, 2006).

Cumprir a sua missão e seguir os legados familiares são formas de lealdade à família que geram um sentido de pertencimento no indivíduo, além da perpetuação da identidade familiar. Pautando-se nessa perspectiva, o presente estudo tem por objetivo abordar o processo de transmissão geracional da profissão em famílias em que houve a repetição da escolha profissional por três gerações seguidas, destacando a discussão a respeito do sentimento de naturalidade da escolha profissional dos membros da família, do peso nome e do sobrenome que carregam e da necessidade de diferenciação da família.

\section{MÉTODO}

Foi realizada uma pesquisa qualitativa, na qual foram entrevistados quinze sujeitos (seis mulheres e nove homens), integrantes de três gerações que seguiram a mesma profissão, de cinco famílias diferentes. Cada família mantinha a tradição em uma determinada profissão, a saber: médicos, advogados, professores de teatro, músicos e psicanalistas.

Os cinco participantes da primeira geração tinham entre 78 e 95 anos, dois estavam aposentados e outros três ainda exerciam a profissão. Em relação à segunda geração, as idades variaram entre 48 e 68 anos e os cinco representantes exerciam a profissão. Quanto à terceira geração, dois sujeitos trabalhavam e três trabalhavam e estudavam (dois cursavam pós-graduação e um a graduação). Nessa geração, os sujeitos tinham idades entre 19 e 38 anos.

Os nomes dos participantes foram alterados, a fim de preservar a identidade dos mesmos. Optou-se por nomear cada família e seus membros com a mesma letra inicial, buscando também manter o padrão dos nomes repetidos e dos nomes compostos. Assim, os entrevistados da família Abreu (advogados), por exemplo, são Antônio ( $1^{\mathrm{a}}$ geração), Antônio José ( $2^{\mathrm{a}}$ geração) e Alex ( $3^{\mathrm{a}}$ geração) e assim por diante com as famílias Borges (músicos), Campos (médicos pediatras), Duarte (professores de teatro) e Esteves (psicanalistas).

Como instrumento de coleta de dados foi utilizado o modelo de entrevista de história de vida, conforme proposto por Bertaux (1997). Utilizou-se um roteiro semiestruturado como base para a condução da entrevista. $\mathrm{O}$ roteiro incluía temáticas referentes à história de vida profissional, tais como a escolha profissional, o desenvolvimento de carreira, a relação entre família e profissão, os valores transmitidos e as expectativas sobre gerações futuras. Não foram feitas perguntas diretivas aos participantes. A entrevista iniciava-se com o estímulo inicial: "Conte-me como se deu a sua escolha profissional", e a partir daí o sujeito ficava à vontade para relatar a sua história (Fernandes, 2010).

Cada participante foi entrevistado individualmente, em local de sua preferência. As entrevistas foram gravadas e transcritas na íntegra e o material obtido foi submetido ao método de análise de conteúdo, conforme proposto por Bardin (2011). Da análise das entrevistas emergiram as seguintes categorias: a naturalidade do processo de escolha profissional; necessidade de diferenciação da família; o peso do nome e do sobrenome; figura mítica familiar; liberdade de escolha na contemporaneidade; valores transmitidos no cotidiano; lealdade ao amor pela profissão. Neste trabalho foram abordadas as três primeiras categorias.

Antes da realização das entrevistas, todos os entrevistados assinaram o Termo de Consentimento Livre e Esclarecido por meio do qual expressaram concordância em participar do estudo e com os procedimentos da pesquisa, estando cientes do comprometimento da pesquisadora em manter o sigilo sobre suas identidades. O projeto foi devidamente aprovado pelo Comitê de Ética da Universidade, sob protocolo número 15/2011.

\section{RESULTADOS E DISCUSSÃO}

\section{A naturalidade do processo de escolha profissional}

A partir das falas dos entrevistados, observouse que uma grande parte dos sujeitos relata que a escolha pela profissão se deu por meio de um processo "natural". Seguir o caminho profissional do pai/mãe/avô/avó foi algo tido como "natural", como se já houvesse um destino sendo traçado para eles. Logo, para as famílias não foi surpresa essa escolha profissional dos membros. Segundo os participantes, coube a eles somente "aceitar" esse destino já traçado, naturalmente, sem grandes questionamentos.

\footnotetext{
“(...) Então a gente sempre fez muita música em casa, sempre frequentamos escola de música e quando eu optei pela universidade eu fiz... fui
} 
levada assim... naturalmente, para o curso de Música. Na verdade eu não pensei em nenhuma outra alternativa, né?" (Beatriz, musicista, 2a geração)

"Então isso era pra mim um caminho muito natural, porque você tá meio que inserido nesse meio, né, então... eu via meu pai, meu avô e tudo..." (Alex, advogado, $3^{\mathrm{a}}$ geração)

"Mas aí, não sei, eu acho que é o caminho natural do filho. (...) eu não me via mesmo fazendo outra coisa." (Caio, médico, $3^{\mathrm{a}}$ geração)

Apesar de considerarem a escolha como um caminho natural, alguns participantes chegaram a pensar em outra(s) possibilidade(s) antes da escolha definitiva, ou ao longo do curso de graduação. Estes apresentaram, inicialmente, alguma resistência em seguir a profissão dos pais/avós, ou seja, em aceitar esse legado dos pais.

"Eu gostava de Medicina, mas me assustei com aquilo. Falei pô, não vou fazer essa tal de Pediatria coisa nenhuma que isso é coisa de maluco. E antigamente era uma loucura, ele (seu pai) atendia essa cidade quase inteira, um desespero. Toda madrugada era: saía, ia atrás de doente, subia morro, descia morro, era uma loucura. (...) Então acho que essa história dele assustou, mas alguma coisa mais forte prendia, né? Tanto que eu falava: não vou fazer isso nunca, a última coisa que eu faço é Pediatria, e no fim fui parar na Pediatria." (Cláudio, médico, $2^{\mathrm{a}}$ geração)

Há também aqueles entrevistados que não apresentaram tal resistência e nem pensaram na possibilidade de seguir outro caminho, a não ser o da profissão que tinham como exemplo em casa. Alguns consideram que, de certa forma, foram preparados ao longo da vida para as respectivas profissões. Isto é, já havia um projeto familiar traçado para eles, ainda que isso não tenha sido dito explicitamente. Para Beatriz $\left(2^{\mathrm{a}}\right.$ geração), por exemplo, houve até certa ingenuidade na aceitação do legado, pois ela nem ao menos questionou a herança familiar.

"Avisei né, que ia fazer Música, e também era mais fácil pra mim assim. Acho que talvez tenha rolado um pouquinho de... de falta de iniciativa pra outra coisa, mas eu achei que de fato, passei no vestibular com facilidade..." (Beatriz, musicista, $2^{\mathrm{a}}$ geração).
Esses resultados demonstram que existem lealdades invisíveis (Boszormenyi-Nagy \& Spark, 1984) presentes nos sistemas familiares, percebidas, principalmente, pela repetição de eventos através das gerações. A lealdade possui um papel fundamental na manutenção da homeostase familiar. Para BoszormenyiNagy e Spark (1984), é como se houvesse um livro simbólico de "prestação de contas" que contabilizasse os créditos e débitos intergeracionais e funcionaria como uma espiral entre a obrigação de dar, a de receber e a de retribuir. Aquele que recebe ficaria em dívida com o membro que deu, sentindo-se na obrigação de retribuir, correspondendo às suas expectativas e assim sucessivamente nas gerações, buscando um equilíbrio nas relações. Manter essa equidade na família é importante porque, segundo Bucher-Maluschke (2008), é ela a promotora da manutenção das relações duradouras e de confiança.

Pode-se considerar que esses membros estão inseridos em um projeto familiar e receberam a profissão dos pais como herança para darem continuidade. De acordo com Tomizaki (2010), cada geração transmite aos seus descendentes aquilo que considera fundamental para a preservação e continuidade da sua herança. Assim, esse projeto, construído de forma coletiva, é o patrimônio ou legado (Boszormenyi-Nagy \& Spark, 1984) recebido que consiste em um mandato geracional que perpassa as gerações na dimensão psíquica e, na maior parte das vezes, de forma inconsciente (BucherMaluschke, 2008).

Para os membros da segunda e da terceira geração, é difícil compreender e explicar o que os levou a escolher a profissão. Isto não fica claro por lhes parecer tão natural. Conforme também observado por Bueno, Souza, Monteiro e Teixeira (2013), os filhos acabam repetindo padrões de funcionamento de outros membros da família, embora muitas vezes não o percebam. Por outro lado, buscam diferenciar-se em alguns aspectos.

Na presente pesquisa há, na maioria dos casos, uma tentativa de diferenciação ao longo da carreira, porém há também, em muitos momentos, uma aproximação dos familiares da primeira geração, como uma forma de pertencimento à família. As suas carreiras são marcadas por oscilações de aproximação e afastamento. Ao mesmo tempo em que buscaram diferenciar-se da família (Bowen, 1965), havia sempre um retorno ao familiar, funcionando como uma espécie de refúgio (Lasch, 1991). Nesse sentido, ressalta-se que sentirse como pertencente ao sistema familiar é importante, pois é no bojo das relações familiares e dos conteúdos transmitidos que o indivíduo se constitui (Minuchin, 1993). 


\section{A necessidade de diferenciação da família}

Foi possível observar que o processo de diferenciação ocorre de forma menos nítida e, muitas vezes, velada na segunda geração e se fortalece na terceira geração. Os representantes da terceira geração demonstram que não se sentem confortáveis ao serem protegidos pela família no âmbito profissional. A busca por um caminho diferente, ou seja, sem a ajuda evidente dos familiares, gera um sentimento de conquista e de mérito próprio, bem como permite uma diferenciação maior daquele sistema.

"E aí o negocio lá no escritório também tinha isso né? Era sobrinho lá do cara. Você vê: sobrinho, né? Imagina se fosse filho? E isso incomodava, isso incomodava um pouco (...) Ai eu fui, pintou uma oportunidade de ir pra (nome da empresa), foi um negócio assim, né? Abriu uma seleção, passei no negócio, passei pra entrevista, fiquei tão satisfeito, falei: tá vendo? Ninguém me indicou, entendeu? Não é porque eu sou filho de ninguém, eu consegui sozinho, foi mérito meu." (Alex, advogado, $3^{\mathrm{a}}$ geração)

Bowen (1998) ressalta a importância do conceito de diferenciação que diz respeito à possibilidade de a pessoa se diferenciar emocionalmente da família de origem. De acordo com Martins, Rabinovich e Silva (2008), pertencer significa sentir-se membro da família e compartilhar de suas crenças, valores, regras, mitos e segredos, ao passo que, diferenciar-se implica uma afirmação da singularidade. Dessa forma, pode-se dizer que, ao seguir a mesma profissão das gerações anteriores, eles asseguram o seu pertencimento à família e, ao questionar o projeto familiar, buscam sua forma própria de fazer e de ser dentro da profissão. $\mathrm{Ou}$ seja, ao mesmo tempo em que eles se se diferenciam, eles também afirmam a sua individualidade.

As falas dos participantes, principalmente daqueles que representam a terceira geração, a respeito de seus projetos profissionais manifestam a busca pela própria identidade, pelo próprio projeto, de forma diferente daquilo que já fora realizado pela família. Apesar de esses projetos serem constituídos também pela influência da vivência em família (Almeida \& Magalhães, 2011; Carreteiro, Pinto, Carvalho, Rodriguez, Alves, \& Estevinho, 2011; Wagner, Tronco, Gonçalves, Demarchi, \& Levandowski, 2012), podem ser autênticos e diferenciados, principalmente na sociedade atual que tem por características a fluidez e a liquidez e que incentiva o indivíduo a criar a si próprio (Bauman, 1998).
"E... a coisa no Teatro, conforme eu fui ficando mais velho, até hoje, foi ganhando mais autonomia assim, eu agora, atualmente, eu tenho o meu grupo (...) e pouco a pouco eu fui me distanciando também da coisa da atuação e fui entrando também nesses outros domínios do Teatro, ligado à escrita e à direção, que é onde eu me sinto mais confortável atualmente porque também foi um espaço que eu criei, (...) Foi algo que já era dado, né, o Teatro e essa formação, mas foi algo que eu nunca, por uma rebeldia, ou por uma certa inquietação nunca aceitei muito como dado, eu sempre quis fazer a minha onda." (Diogo, professor de teatro, $3^{\mathrm{a}}$ geração)

Para Diogo, "criar a sua própria onda" foi descobrir uma forma de dar prosseguimento ao legado familiar, porém destacando a sua individualidade e descobrir um modo de fazer a profissão adaptada aos dias de hoje. O mundo do trabalho hoje exige novos desafios (Cavazzote, Lemos, \& Viana, 2012) e configura-se de forma bem diferente em relação ao contexto em que os membros da primeira e da segunda geração fizeram a escolha profissional, há cerca de 60, 70 anos e 30, 40 anos, respectivamente. De acordo com Marques (2004), o mercado de trabalho exige hoje o "espírito empreendedor" que produz inovações e que vem associado a um modo particular de abordar problemas.

De fato, no mundo contemporâneo, a identidade deve ser construída reflexivamente em meio a uma diversidade de opções e possibilidades que se apresentam (Giddens, 2002). Segundo Bauman (1998), o projeto moderno transformou a identidade em uma realização, fazendo dela uma tarefa de responsabilidade do indivíduo.

“(...) parece um lugar também de muita conquista pessoal, um lugar que eu fui por mim mesmo, tentando criar, construir esse espaço. No meu caso, essa coisa individual foi muito forte para eu poder me diferenciar dentro dessa tradição familiar que eu já vinha (...)” (Diogo, professor de teatro, $3^{\mathrm{a}}$ geração)

“(...) foi um custo danado pra eu me apropriar da Psicanálise como uma coisa minha e não de outros, né? Porque tem uma questão da identificação e o que que você faz com isso, né? Você tem que se apropriar das coisas e outras coisas deixar pra lá, não é seu." (Érica, psicanalista, $3^{\text {a }}$ geração)

Apropriar-se da profissão e traçar sua trajetória de modo singular implica sair do lugar de herdeiro 
passivo, apropriando-se do seu destino com autoria. É conseguir conjugar a herança da tradição familiar com aquilo que the é singular, apoderando-se do que lhe foi legado, porém de forma mais independente e autônoma. Significa também não viver à sombra dos pais/avós e não depender de sua fama ou reconhecimento. Diferenciar-se na contemporaneidade implica ser criativo, fazer-se sujeito do seu próprio projeto (Velho, 1981) e estar constantemente se reinventado (Giddens, 2002). De acordo com Carreteiro (2009; 2011), a ideologia individualista que predomina na contemporaneidade leva o sujeito a se perceber como se fosse o grande responsável por sua carreira e por seu sucesso ou fracasso.

\section{O peso do nome e do sobrenome}

Os participantes relataram que existe um peso e uma cobrança por carregarem sobrenomes famosos e reconhecidos em suas áreas de atuação profissional. A maioria dos membros da segunda e da terceira geração relatou sentir forte pressão por parte da sociedade - outros familiares, professores, colegas de profissão - além de uma alta exigência pessoal, relativa ao desempenho profissional. A cobrança interna, ou seja, do próprio sujeito, diz respeito à necessidade de ser tão bem-sucedido quanto os membros das outras gerações e à responsabilidade que sente em fazer jus ao sobrenome da família. Isto acaba por provocar comparações com outros profissionais da família e dúvidas em relação à capacidade individual. A pressão social é marcada pela referência que o sobrenome representa na área de atuação, gerando uma alta exigência quanto ao desempenho da profissão.

“É um peso. Não é bom, não recomendo. Talvez por isso mesmo que eles tentaram me dissuadir a seguir, porque sabiam que ia ser um peso muito maior, você tem que ser o filho de fulano, é duro, é duro." (Ernesto, psicanalista, $2^{\circ}$ geração)

“(...) tem a responsabilidade, né? Quer dizer, todo mundo espera que você seja bom justamente por causa do nome, que você faça jus ao nome, que você fique correspondente a isso daí. Então há uma cobrança muito grande." (Alex, advogado, $3^{\mathrm{a}}$ geração)

“É, tem uma pressão (risos). Mas é uma pressão que não é proposital, que tá lá no ar. Ninguém põe a pressão não. Mas, existe. Pois é, eu não sei o que os professores lá na faculdade acham de mim. Todos os professores conhecem minha avó, minha mãe. 'Ah, filho da Bia'... Ai eu penso: 'será que ele gosta de mim porque eu sou um bom aluno?", (Bruno, músico, $3^{a}$ geração)

De acordo com Schutzemberger (2011), o sobrenome é uma das bases da identidade e é por intermédio dele que a pessoa se situa social, geográfica e culturalmente, adquirindo o sentido de pertencimento a um determinado grupo. O sobrenome marca a relação do indivíduo com seus ancestrais, inscrevendo-o em uma linhagem e vinculando a sua identidade à história das gerações (Gaulejac, 2009).

Gaulejac (2009) questiona como é possível existir por si mesmo quando a pessoa já carrega um sobrenome ilustre, uma vez que este é um elemento incontornável do processo de identidade. Conforme este autor, o sobrenome permite reconhecer-se e ser reconhecido, identificar-se e ser identificado e a sua abolição seria uma forma de despersonalização.

Quanto à importância atribuída ao sobrenome na constituição da identidade do sujeito, os entrevistados desse estudo relatam que socialmente há a cobrança de uma expectativa a ser correspondida. Segundo Barros (1987), a disposição em transmitir aos filhos e netos o nome da família refere-se à inserção da família na sociedade, além de satisfazer aos cultos e às tradições familiares. Isto demonstra a importância que o sobrenome possui na sociedade, e colabora para a compreensão acerca da angústia, relatada por alguns entrevistados, relacionada à cobrança em corresponder às expectativas projetadas, muitas vezes sob a pena de não ser reconhecido como um profissional, sendo desleal à família (DucommunNagy, 2006).

“Às vezes eu acho que eu fico aflita não de honrar o sobrenome, mas muito mais de acharem que eu tenho que ser qualquer coisa porque eu tenho o sobrenome na área, achar que vão me cobrar mais por causa disso, ou sei lá o quê." (Érica, psicanalista, $3^{\mathrm{a}}$ geração)

"Uma pressão que as pessoas já logo querem cobrar: 'pô, você é filho do fulano', pô, né, ai você já fica naquela situação assim: 'eu não posso decepcionar, né?’ Mas nunca tive medo não, talvez por ter ficado longe e tal. Eu nunca me senti muito cobrado, mas você sabe que tem uma responsabilidade maior, né, você fica com uma responsabilidade de não é... não decepcionar, né, então você acaba tendo que se superar mais, estudar mais, tomar mais cuidado..." (Cláudio, médico, $2^{\mathrm{a}}$ geração) 
Seguir a carreira de outros membros da família pode também "abrir caminhos", isto é, ser uma via de sucesso facilitada pelo que o grupo familiar já construiu e até mesmo pela referência que a família e o sobrenome são em determinada área profissional. O nome de família é considerado um capital social (Bourdieu, 1998) à medida que funciona como um recurso de vinculação ao grupo e relaciona-se ao conhecimento e ao estabelecimento de contatos. Dessa forma, os detentores do capital social herdado, representado por um sobrenome importante em uma determinada área, acabam sendo valorizados por esse fator, usufruindo de facilidades no caminho em direção ao prestígio social (Bourdieu, 1998).

"Você segue a carreira do seu pai, do seu avô, as pessoas reconhecem pelo nome, né, quer dizer, as pessoas, mesmo quem não me conhece, me reconhece pelo sobrenome que é um sobrenome que tem uma referência (...) Isso por um lado é bom, que te ajuda a abrir portas, sem dúvida alguma, né?" (Alex, advogado, $3^{\mathrm{a}}$ geração).

"Mas na grande maioria dos casos eu digo que abre portas, mas também tem essas... esses problemas, esse obstáculos, que não têm nada a ver comigo. Mas de forma geral acho que o saldo é positivo. É algo que demorou, mas que eu já estou nesse processo e esses signos que vêm da minha família quando colocados ao meu favor eles ficam muito fortes, dão mais sentido pra coisa" (Diogo, professor de teatro, $3^{\mathrm{a}}$ geração).

Se carregar o sobrenome da família pode ser um peso, o fardo pode tornar-se mais pesado quando o nome próprio é o mesmo, como o é o caso de Antônio José, que tem como primeiro nome o nome de seu pai, Antônio. De acordo com Krom (2000), muitas vezes, a repetição dos nomes próprios na família está relacionada, frequentemente, às lealdades invisíveis (Boszormenyi-Nagy e Spark, 1984).

Ao escolher o nome, os pais fazem ao filho a doação de uma história imaginária e simbólica familiar, inserida na continuidade da filiação (Tesone, 2009). Assim, ao dar o nome do pai a um filho, o indivíduo já nasce com uma missão a ser realizada ao longo da vida, que, em geral, vem carregada da expectativa de perpetuação da linhagem. Segundo Cerveny e Rabinovich (2006), a história de cada um enquanto sujeito inicia-se em uma pré-história que antecede o nascimento, em que é tecida uma trama de expectativas, fantasias e desejos dos ascendentes.
"Eu acho que um dado que de certa maneira me incomodava no início da carreira era o fato justamente de eu ser filho do meu pai, quer dizer, filho de uma pessoa que tem o mesmo nome que eu e que é conhecida, famosa, tem um nome de sucesso. Porque aí, isso pra mim, isso me abafava um pouco, então eu buscava os meus caminhos próprios (...) isso é um peso." (Antônio José, advogado, $2^{\mathrm{a}}$ geração)

No caso de Antônio José, levar o nome e o sobrenome do pai, uma pessoa reconhecida no campo profissional, foi um incômodo, mas também algo que o levou a buscar uma diferenciação, como forma de evitar o inevitável: a vinculação de seu nome com o nome de seu pai. O nome e o sobrenome atribuem um lugar para o indivíduo no seio da família e na sociedade, permitindo que ele seja distinguido dos outros, ou seja, conferindolhe identificação e diferenciação. Essa contradição entre integrar-se e diferenciar-se, segundo Gaulejac (2009), evoca a similaridade, ou seja, o indivíduo sente que se assemelha aos membros da família, ao mesmo tempo em que evoca a diferenciação, isto é, o indivíduo é definido por suas próprias características que o tornam diferente dos outros. Conforme este autor, esta seria a maior contradição identitária: o nome confere o pertencimento à família, assim como o reconhecimento da individualidade.

\section{CONSIDERAÇÕES FINAIS}

Observou-se que seguir a profissão dos familiares, na percepção dos participantes da pesquisa, é algo considerado como um caminho "natural", como se já tivesse sido traçado, ainda que nenhum dos sujeitos entrevistados tenha sido pressionado a segui-lo. A influência da família na escolha profissional dos participantes não se deu de forma explícita, ou seja, não houve, na maioria dos casos, desejo expresso verbalmente de que os filhos/netos seguissem a mesma profissão. Os resultados aqui apresentados vão de encontro àqueles obtidos por Andrade (1997). O autor pesquisou famílias nas quais várias gerações vinham se dedicando à mesma carreira, gerando grandes nomes em suas respectivas áreas e observou que muitos dos seus entrevistados foram forçados a seguir as carreiras familiares. Na presente pesquisa, nenhum dos sujeitos sentiu-se forçado a seguir a carreira dos pais/avós. Pelo contrário, muitos pais/mães/avós optaram por nada falar, com receio de influenciar, e outros tentaram dissuadir os filhos/netos de seguir a profissão familiar. Porém, ainda assim, os descendentes acabaram por escolhê-la. A repetição da escolha profissional na 
família, considerada a partir do processo de transmissão geracional, aponta para a importância dos vínculos de leadade familiares e leva à continuidade e perpetuação da identidade familiar.

Ao escolher a mesma profissão dos pais/avós, os sujeitos dão continuidade ao legado familiar, porém sentem uma necessidade de diferenciar-se, apropriando-se da profissão e fazendo "do seu jeito", reafirmando, assim, a sua individualidade. A busca pela diferenciação, em alguns casos, está relacionada à forma de lidar com o peso do sobrenome - ou do nome, em caso de repetição deste - que carregam devido ao grande prestígio da família na área profissional.

Pode-se dizer que a transmissão geracional da profissão na contemporaneidade existe, porém não enraizada de modo tão literal, como se dava no passado, quando as terras ou o estabelecimento de trabalho eram necessariamente passados de pai para filho. Considerase que ela se dá de forma mais fluida, ela se espalha de modo subliminar, engendrando escolhas aparentemente livres e individuais, ancoradas em lealdades invisíveis que perpassam as expectativas familiares, consciente e/ou inconscientemente.

Este estudo apresenta limitações em face da sua natureza qualitativa. As entrevistas foram realizadas com um número restrito de sujeitos, de modo que os temas pudessem ser investigados em profundidade, alcançando as singularidades de cada família. Assim, o objetivo não foi generalizar os resultados, considerando que cada família possui a sua história e as suas particularidades.

Os resultados deste trabalho apontam para a pertinência da realização de outras investigações, visando ao aprofundamento da compreensão dos processos de transmissão geracional relacionados à escolha profissional. Esse fenômeno, embora seja menos frequente na contemporaneidade, ilustra a importância da transmissão geracional na constituição subjetiva e, particularmente, na construção de projetos de vida.

\section{REFERÊNCIAS}

Almeida, M. E. G. G. \& Magalhães, A. S. (2011). Escolha profissional na contemporaneidade: projeto individual e projeto familiar. Revista Brasileira de Orientação Profissional, 12(2), 205-214.

Andolfi, M., Angelo, C., Menghi, P., \& Nicolo-Corigliano, A. M. (1984). Por trás da máscara familiar: um novo enfoque em terapia familiar. Porto Alegre: Artes Médicas.

Andrade, T. D. (1997). A família e a estruturação ocupacional do indivíduo. In R. S. Levenfus, et al. Psicodinâmica da escolha profissional (pp. 123-134). Porto Alegre: ArtMed.

Bardin, L. (2011). Análise de conteúdo. Edição revista e ampliada. Lisboa: Edições 70.
Barros, M. L. (1987). Autoridade e afeto: avós, filhos e netos na família brasileira. Rio de Janeiro: Jorge Zahar.

Bauman, Z. (1998). O mal-estar da pós-modernidade. Rio de Janeiro: Jorge Zahar.

Bertaux, D. (1997). Les récits de vie: perspectives ethnosociologiques. Paris: Nathan.

Boszormenyi-Nagy, I. \& Spark, G. (1984). Invisible loyalties. Levittown: Brunner/Mazel.

Bourdieu, P. (1998). Futuro de classe e causalidade do provável. In M. C. Nogueira \& A. Catani (Orgs.). Escritos de educação (pp. 81-126). Petrópolis, RJ: Vozes.

Bowen, M. (1965). Family psychotherapy with schizophrenia in the hospital and in private practice. In I. Boszormenyi-Nagy \& J. L. Framo (Eds.). Intensive family therapy: theoretical and practical aspects (pp. 213-243). New York: Harper \& Row.

Bowen, M. (1998). De la familia al individuo: la diferenciación del sí mismo en el sistema familiar. Barcelona: Paidos.

Bucher-Maluschke, J. S. N. F. (2008). Do transgeracional na perspectiva sistêmica à transmissão psíquica entre as gerações na perspectiva da psicanálise. In M. A. Penso \& L. F. Costa (Orgs.). A transmissão geracional em diferentes contextos: da pesquisa à intervenção (pp. 76-96). São Paulo: Summus.

Bueno, R. K., Souza, S. A., Monteiro, M. A., \& Teixeira, R. H. M. (2013). Processo de diferenciação dos casais de suas famílias de origem. Psico, 44(1), 16-25.

Carreteiro, T. C. (2009). Pais e filhos adolescentes construindo sentidos, ideais de trabalho e projetos profissionais. In T. FéresCarneiro (Org.). Casal e família: permanências e rupturas (pp. 253-272). São Paulo: Casa do Psicólogo.

Carreteiro, T. C. (2011). História de vida laboral familiar em duas gerações: trabalho e contextos sociais. In T. Féres-Carneiro (Org.). Casal e Família: conjugalidade, parentalidade e psicoterapia (pp. 119-132). São Paulo: Casa do Psicólogo.

Carreteiro, T. C., Pinto, B. O. S., Carvalho, C. G., Rodriguez, L. S., Alves, V. B., \& Estevinho, W. L. (2011). Juventudes e Trabalho: aproximações e diferenças da concepção de trabalho nos diferentes contextos juvenis. Ecos: Estudos Contemporâneos da Subjetividade, 1(1), 135-143.

Cavazzote, F. S. C. N., Lemos, A. H. C., \& Viana, M. D. A. (2012). Novas gerações no mercado de trabalho: expectativas renovadas ou antigos ideais? Cadernos EBAPE.BR, 10(1), 162-180.

Costa, L. F. (2010). A perspectiva sistêmica para a clínica da família. Psicologia: Teoria e Pesquisa, 26(n. esp.), 95-104. http://dx.doi. org/10.1590/S0102-37722010000500008

Ducommun-Nagy, C. (2006). Ces loyautés qui nous libèrent. Paris: JC Lattès.

Falcke, D. \& Wagner, A. (2005). A dinâmica familiar e o fenômeno da transgeracionalidade: definição de conceitos. In A. Wagner (Coord.). Como se perpetua a família? A transmissão dos modelos familiares (pp. 25-46). Porto Alegre: EDIPUCRS.

Fernandes, M. E. (2010). História de vida: dos desafios de sua utilização. Revista Hospitalidade, 7(1), 15-31.

Gaulejac, V. (2009). L'histoire em héritage: roman familial et trajectoire sociale. Paris: Desclée de Brouwer.

Giddens, A. (2002). Modernidade e identidade. Rio de Janeiro: Jorge Zahar Editor.

Krom, M. (2000). Família e mitos, prevenção e terapia: resgatando histórias. São Paulo: Summus.

Lasch, C. (1991). Refúgio num mundo sem coração. A família: santuário ou instituição sitiada? Rio de Janeiro: Paz e Terra.

Marques, J. C. (2004). O mundo do trabalho e suas complexidades. In J. C. Sarriera, K. B. Rocha, \& A. Pizzinato (Orgs.). Desafios do mundo do trabalho: orientação, inserção e mudanças (pp. 13-31). Porto Alegre: EDIPUCRS. 
Martins, E. M. A., Rabinovich, E. P., \& Silva, C. N. (2008). Família e diferenciação na perspectiva de Murray Bowen: um estudo de caso, Psicologia USP, 19(2), 181-197. http://dx.doi.org/10.1590/ S0103-65642008000200005.

Minuchin, S. (1993). Famílias, funcionamento e tratamento. Porto Alegre: Artes Médicas.

Schutzemberger, A. A. (2011). Ay, mis ancestros! Buenos Aires: Aguilar, Altea, Taurus, Alfaguara.

Soares-Lucchiari, D. H. (1997). Uma abordagem genealógica a partir do Genoprofissiograma e do Teste dos Três Personagens. In R. S. Levenfus et al. Psicodinâmica da escolha profissional (pp. 135-170). Porto Alegre: ArtMed.

Tesone, J. E. (2009). Inscrições transgeracionais no nome próprio. Jornal de Psicanálise, 42(76), 137-157.

Tomizaki, K. (2010). Transmitir e herdar: o estudo dos fenômenos educativos em uma perspectiva intergeracional. Educação $e$ Sociedade, 31(111), 327-346.

Velho, G. (1981). Individualismo e cultura - notas para uma antropologia da sociedade contemporânea. Rio de Janeiro: Zahar Editores.
Wagner, A., Tronco, C. B., Gonçalves, J. S., Demarchi, K. A., \& Levandowski, D. C. (2012). Projetos para os filhos e estratégias de socialização:a perspectiva de pais e mães. Psicologia \& Sociedade, 24(1), 122-129. http://dx.doi.org/10.1590/S010271822012000100014

Autores:

Maria Elisa Almeida - Pós-doutoranda do Departamento de Educação da Pontifícia Universidade Católica do Rio de Janeiro.

Andrea Seixas Magalhães - Professora Adjunta do Departamento de Psicologia da Pontifícia Universidade Católica do Rio de Janeiro.

Terezinha Féres-Carneiro - Professora Titular do Departamento de Psicologia da Pontifícia Universidade Católica do Rio de Janeiro.

Endereço para correspondência:

Maria Elisa Almeida

Pontifícia Universidade Católica do Rio de Janeiro

Departamento de Educação

Rua Marquês de São Vicente, 225/1049L - Gávea

CEP 22451-900 Rio de Janeiro, RJ, Brasil

E-mail: elisagua@gmail.com

Recebido em: 11.10 .13

Aceito em: 11.07.14 